Article

\title{
How High-Quality Urbanization Affects Utilization Efficiency of Agricultural Water Resources in the Yellow River Basin under Double Control Action?
}

\author{
Xiling Zhang ${ }^{1}$, Yusheng Kong ${ }^{1, *}$ and Xuhui Ding ${ }^{1,2, *}$ \\ 1 School of Finance and Economics, Jiangsu University, Zhenjiang 212013, China; celinezh10@gmail.com \\ 2 Institute of Industrial Economics, Jiangsu University, Zhenjiang 212013, China \\ * Correspondence: 1000001042@ujs.edu.cn (Y.K.); dingxh@ujs.edu.cn (X.D.)
}

Received: 12 March 2020; Accepted: 1 April 2020; Published: 3 April 2020

\begin{abstract}
To promote the high-quality development of the Yellow River Basin, the total amount and intensity of agricultural water must be controlled. Further speaking, an urbanization development system should be established that is compatible with water resources and the water environment. We adopted the stochastic frontier analysis model to measure the agricultural water utilization efficiency of the Yellow River Basin from 2007 to 2017. We also adopted the dynamic panel difference generalized method of moments (GMM) and system GMM models to verify the driving factors, in which population urbanization, economic urbanization, and equilibrium urbanization levels were selected as the key variables. The results show that the overall efficiency of agricultural water utilization maintained a steady upward trend during the research period. The spatial differentiation was generally characterized by higher efficiency levels in the eastern region and lower levels in the western region. The variation coefficient of water utilization efficiency showed a downward trend in general, which indicates a space spillover effect. Agricultural water utilization efficiency continued to converge from 2007 to 2017, and the upper reaches area converged relatively more quickly. Regarding the influencing factors, the population urbanization, economic urbanization, balanced urbanization, crop planting ratio, and rice planting ratio had negative effects on agricultural water utilization efficiency. Urbanization did not positively affect agricultural water use efficiency as the related theories, so urbanization quality and urban-rural integration should be paid more attention. However, technology innovation was significantly positive in agricultural water utilization efficiency. The influencing factors of per capita water availability and annual precipitation did not pass the significance test. Therefore, the government should vigorously promote the development of high-quality new-type urbanization, scientifically formulate the scale and speed of urbanization, strengthen the urban, rural, and industrial integration, and promote the adjustment of planting structures and agricultural deep processing.
\end{abstract}

Keywords: water utilization efficiency; high-quality urbanization; double control action; the Yellow River Basin

\section{Introduction}

As an important ecological barrier and economic belt in China, the Yellow River Basin faces ceilings for water resources and the ecological environment in promoting high-quality development. Promoting the sustainable utilization of agricultural water resources is essential for high-quality development in the Yellow River Basin. As can been seen in Figure 1, the provinces of the Yellow River Basin can be divided into three regions, including the eastern, central, and western region. 
The total population of the nine provinces of the Yellow River Basin is 420 million, with a watershed area reaching 795,000 $\mathrm{km}^{2}$. In 2018, the average precipitation in the Yellow River Basin was $551.6 \mathrm{~mm}$. The measured runoffs of its mainstream Lanzhou, Huayuankou, and Lijin Stations were 44.176, 44.78, and 33.38 billion $\mathrm{m}^{3}$. In this study, we selected provinces as the research objects to obtain better data and enable horizontal comparisons. The total agricultural output value was only 1.95 trillion yuan in the same period, supporting $30.3 \%$ of the country's population, and producing $35 \%$ of the country's food in 2018 [1]. The proportion of agricultural water utilization in the major provinces of the Yellow River Basin was 30-91\% in 2017, but only $60 \%$ of the entire river basin reached the water quality target. According to national standards for surface water, there are five types of water quality. The higher the category, the worse the water quality. Class III is mainly applicable to fishery waters and swimming areas. A water quality below Class III is poor and cannot be used as a source of drinking water. Class V water is mainly suitable for agricultural water areas and waters with general landscape requirements. Inferior Class V water is more polluted than Class V surface water, indicating that water use functions have basically been lost [2].

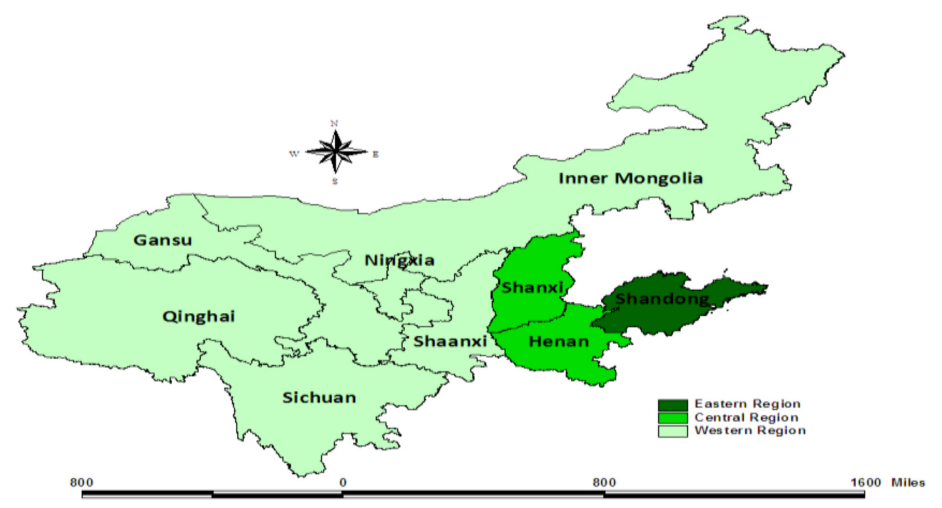

Figure 1. The geographical map of the Yellow River Basin in China.

The length of the entire Yellow River Basin evaluated for water quality was 22,891.9 km, of which 29.1\% was inferior to Class III water. Among the 137 water quality sections of the Yellow River in 2018, the proportion of water categorized as worse than Class V was $12.4 \%$, which was much higher than the national average level of 6.7\% [3]. Many prominent problems are being faced in the Yellow River Basin. First, the ecological environment of the river basin is fragile, and the water conservation capacity has seriously decreased. Second, the Yellow River Basin suffers various kinds of pollution from industrial, urban life, and agricultural non-point sources. The total water resources of the Yellow River are less than $7 \%$ of the Yangtze River, and the per capita share is only $27 \%$ of the national average. Water resources are used extensively, and agricultural water utilization efficiency is low. The development and utilization rate of water resources is as high as $80 \%$, which is far beyond the ecological warning line of $40 \%$ for general river basins. In the context of prioritizing the development of green ecology, China strongly emphasizes the coordinated development of urbanization and agricultural modernization. The urbanization development of the Yellow River Basin has increased from $26.29 \%$ to $56.23 \%$ in the past 20 years. Figure 2 shows that the differences in water consumption and wastewater discharge among provinces are significant with different levels of economic and society development. The wastewater discharge increased from 124.95 billion tons in 2007 to 180.06 billion tons in 2017. The annual growth rate was 3.78\%, which was higher than the national average level (Liu, 2020) [4]. Xi (2016) proposed a double control action of the total amount and intensity of water consumption, which has become the biggest constraint on high-quality development, especially for the Yellow River Basin. Xi stated in 2019 that we must promote the sustainable and effective use of water resources. We must persist in regulating the city by water, land by water, people by water, and production by water to take water resources as the most important and rigid constraint and rationally plan population, urban, and industrial development [5]. In this study, we mainly explored the internal mechanism of the 
supportive effects of urbanization development on agricultural water utilization efficiency in the Yellow River Basin, which also has important practical significance for promoting the scientific allocation of agricultural water resources and high-quality urbanization in the Yellow River Basin.

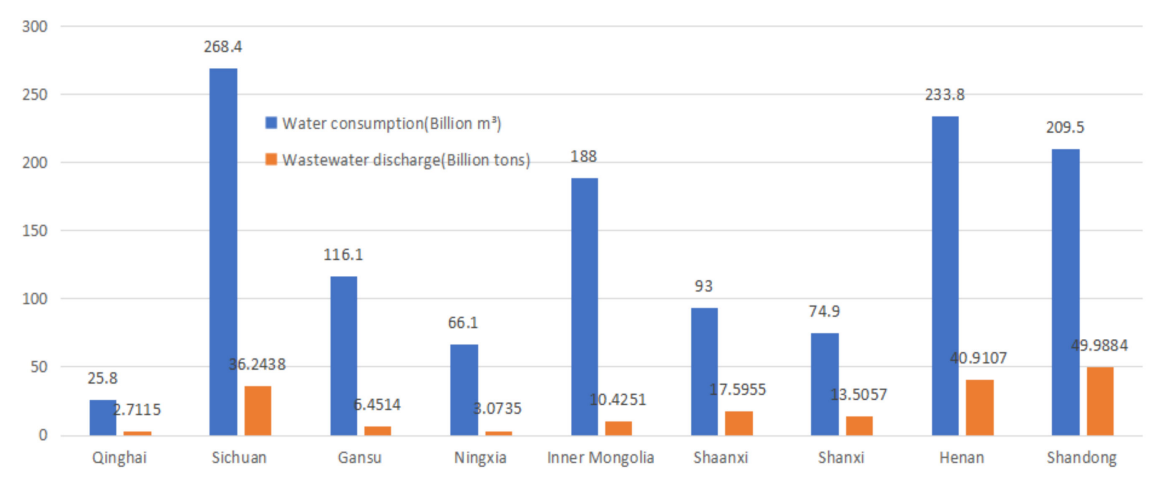

Figure 2. The histogram of water consumption and wastewater discharge of interprovincials in 2017.

The existing domestic and foreign literature on water resource utilization efficiency research mainly focuses on single-factor and total-factor water utilization efficiency. Single-factor water efficiency has some shortcomings and is rarely used. Generally, research methods include principal component analysis, data envelopment analysis (DEA), and stochastic frontier analysis (SFA) [6-8]. Earlier scholars regarded Gross Domestic Product (GDP) as the only output, and some scholars later included the non-desirable output of water resource utilization and effective decision-making on green development concepts into their research studies [9-11]. Agricultural production is the basis for maintaining human survival. As the demand for agricultural water increases, the inefficient agricultural use of water worsens the water shortage problem. Some researchers have begun to focus on agricultural or irrigation water efficiency to replace the simple water consumption per 10,000 yuan of GDP. Compared with the overall efficiency of regional water utilization, the total power of agricultural machinery is generally used as an indicator of fixed assets investment in the agricultural production field. The total planting ratio is also used as an additional input indicator in combination with the natural characteristics of agricultural production [12]. In the analysis of the potential for improvement in agricultural water efficiency, research was mostly conducted from the macro-areas and micro-farmers' perspectives; empirical tests were mostly conducted from macro-factors, such as natural conditions, industrial structure, water resources' endowment structure, and education per capita [13]. In terms of the micro-farm household level, research was mainly conducted on field adjustments to analyze the effects of farmer planting operations, farmer characteristics, water-saving consciousness, irrigation technology, and co-irrigation methods [14-17].

Urbanization reflects the transition process from the rural system to the urban system, manifested in the spatial agglomeration of the population, the conversion of land use, and the structural change of the industry. Urbanization has an important impact on agricultural structure, agricultural production efficiency, and technological level [18-20]. The new-type urbanization construction takes urban-rural coordinated development, agricultural interaction, intensive economy, and ecological livability as the basic requirements, for the coordination of urban and new-type rural communities [21,22]. The research on urban-rural interaction mainly focused on the coupling of urbanization and rural development, the development path of urban-rural interaction, and the evaluation of urban-rural integration. Many studies also focused on urbanization and agricultural water conservation, urbanization and water resource use and distribution, urbanization development, and agricultural modernization [23-25]. To coordinate the amount of water available, the amount of savable water, and the capacity of the water function area to accept pollution, Feng (2018) built a threshold calculation model for urbanization levels under the constraints of "three red lines" in water resource management [26]. Jin (2018) studied the impact of urbanization on water consumption from the perspective of population structure change. The ageing population has a large elastic coefficient on water consumption, especially in the eastern 
region [27]. To date, domestic and foreign researchers have studied the problem of water resource constraints in the process of urbanization in great depth, but some experts have now begun to pay attention to the evolution of agricultural water use, ecological constraints, and urban-rural water use linkage models in the process of urbanization or industrialization [28]. Wang and Yan interpreted the theoretical connotation and practical cases of double control actions in detail, and proposed that the system feedback mechanisms of water resources, the economic society, and ecological environment should be fully considered [29,30]. However, studies are lacking in the supportive effects of new-type urbanization on agricultural water utilization efficiency, and in investigations of the regional differentiation and dynamic evolution of agricultural water efficiency from the perspective of urbanization quality. Few studies have examined wastewater discharge or non-point source pollution in agricultural production. As such, we examined the supportive effects on agricultural water utilization from the perspective of new-type urbanization, and provide policy references for agricultural water consumption control and green development.

\section{Model Construction}

\subsection{Stochastic Frontier Analysis Model (SFA)}

The stochastic frontier analysis (SFA) model is a parameters research method of the stochastic frontier model with a random disturbance term. The model sets the output as a function of non-negative random error as technical inefficiency, and systematic random error as noise, which was first proposed by Aigner et al. [31]. SFA uses maximum likelihood estimation (MLE) to determine the frontier boundary. The technical efficiency can be measured by only one estimation, and SFA can be used to analyze the distribution mean of technical efficiency as a function of the influencing factors of efficiency. Thus, the indistinguishable defects of the influencing factors on the output of the uncertainty method are avoided, and the method is suitable for panel data analysis. The limitations of the DEA method include the following: First, the method assumes that all efficiency factors are covered by the model, and that there are no non-investment factors (also known as environmental factors). Second, the method is a mathematical planning method. The suitability of the calculation model cannot be tested. Third, although the method has the advantage of a computable multi-output model, in terms of economic significance, multiple outputs must be uncorrelated. Fourth, the rank correlation test needs to be performed on the calculated data first. For the SFA method, this is not as convenient as in the DEA method when dealing with the situation of multiple inputs and multiple outputs. In addition, the sample size needs to be large enough. Compared with DEA, SFA incorporates the classic white noise term, while describing the process of the production accurately. The influence of random factors on the frontier is avoided to some extent, which is more in line with the essential characteristics of agricultural production. SFA can be used to study traditional hypothesis testing. In formula (1), $Y$ is agricultural output and $X$ is various agricultural input factors, $f\left(x_{i t}, \beta\right)$ is the deterministic frontier output part of the stochastic frontier function, $t$ is the time trend and reflects the technological changes, and $\beta$ is the parameter to be estimated. $v_{i t}$ is a random disturbance term, assuming that it follows an independent and identically distributed normal distribution: $v_{i t} \sim N\left(0, \sigma_{v}^{2}\right)$, and $u_{i t}$ is a non-negative random variable, which reflects the loss of production allocation efficiency, and represents the distance from the actual production point to the production front. Also the formula assumes that it follows the truncated normal distribution: $u_{i t} \sim N\left(0, \sigma_{u}^{2}\right)$, and independent of $v_{i t} ; v_{i t}-u_{i t}$ is the optimal technical deviation. According to the research of Meeusen and Van Den Broeck (1977), and Kumbhakar and Lovell (2000) [32,33], the panel data form of SFA is shown in formula (2). Lei (2015) and Wang (2010) adopted the SFA method to measure the efficiency of industrial and agricultural water use separately. However, some experts have suggested that the data results obtained by the SFA and DEA methods have significant correlation and good consistency [34,35].

$$
Y_{i t}=f\left(x_{i t}, \beta\right) \exp \left(v_{i t}-u_{i t}\right), \mathrm{T} E_{i t} \exp \left(-u_{i t}\right), u_{i t}=u_{i} \exp (-\eta(t-T))
$$




$$
\ln Y_{i t}=\ln f\left(x_{i t}, \beta\right)+v_{i t}-u_{i t}, i=1,2, \cdots, N ; t=1,2, \cdots, T v_{i t} \sim N\left(0, \sigma_{v}^{2}\right), u_{i t} \sim N\left(0, \sigma_{u}^{2}\right)
$$

\subsection{Dynamic Panel Data Model}

The dynamic panel data model reflects the dynamic nature of economic behavior development and helps solve the problem of endogenous and missing variables, so can better reflect the changing trend of efficiency. It has the advantages of controlling heterogeneity, reducing multiple collinearity, reducing data bias, and standardizing asymptotic distribution [36]. The data in this paper are the balanced panel data composed of time series data from nine provinces in the Yellow River Basin from 2007-2017; therefore, the models related to panel data are suitable for quantitative analysis. Agricultural water utilization efficiency is characterized by continuous dynamics, and water utilization efficiency in each year directly affects water utilization efficiency in the next year. Therefore, it was more reasonable to adopt a dynamic panel data model to conduct our research. $y_{i t}$ is the explained variable in formula (3), $y_{i, t-1}$ is the lag term of the explained variable, $x_{i t}^{\prime}$ is the explanatory variable, and $\varepsilon$ is the random disturbance term. The more general dynamic panel model in formula (4), multi-order lag terms of the explained variables, can be included in the explanatory variables. The effects of lag terms, such as $y_{i, t-2}$ or $y_{i, t-p}$ on the explained variables are also considered in the dynamic panel regression model [37]. In the dynamic panel data model estimation process, generalized method of moments (GMM) estimation methods can be used. The difference GMM method proposed by Arellano and Bond (1991) and the system GMM method proposed by Blundell and Bond (1998) is based on the difference GMM method. Both can be used to solve the problem of reverse endogeny of the explained variables and improve the accuracy of the estimated variables [38-40]. As for the advantages of the system GMM, it can improve the estimation efficiency and estimate the coefficient of the variable $z_{i}$ that does not change with time. In terms of the disadvantages, the lag term must be assumed to be independent of the individual effect, $u_{i}$. The system GMM cannot be used if this condition cannot be met [41-43]. Song (2019) used difference GMM and system GMM regression models to analyze the urbanization development in China [44]. Ma (2018) took a two-stage system GMM to analyze the impact of economic aggregation on water consumption, in order to fully test the variable endogeneity [45].

$$
\begin{gathered}
y_{i t}=\alpha+\rho y_{i, t-1}+x_{i t}^{\prime} \beta+z_{i}^{\prime} \delta+u_{i}+\varepsilon_{i t} ;(t=2,3 \ldots \ldots T) \\
y_{i t}=\alpha+\rho_{1} y_{i, t-1}+\rho_{2} y_{i, t-2}+\cdots \ldots+\rho_{p} y_{i, t-p}+x_{i t}^{\prime} \beta+z_{i}^{\prime} \delta+u_{i}+\varepsilon_{i t}
\end{gathered}
$$

\section{Empirical Estimation}

\subsection{Efficiency Estimation of Agricultural Water Utilization}

We selected the data of the nine provinces in the Yellow River Basin from 2007 to 2017. To yield the economic returns, water resources need to utilize other production factors in agricultural production activities. Water consumption cannot be directly linked to regional economic growth. Therefore, we used the agricultural added value of each province in each year as an output variable. Water resources, labor, and capital were integrated into the input, and the input factors were selected, including labor, fixed assets, crop planting ratio, agricultural water, and agricultural fertilizer. First, the number of employees in the primary industry in each province were selected as the labor index to represent labor input. However, this refers to the total labor force of agriculture, forestry, animal husbandry, and fisheries, excluding the labor force engaged in industries and services in rural areas. Second, the total power of agricultural machinery was selected as the fixed asset input index. The large-scale use of advanced production materials, such as agricultural machinery, has markedly increased agricultural production and could release a lot of surplus labor. Third, we learned from studies, such as Cao et al. (2013) and $\mathrm{Wu}(2016)$ that land input is expressed in terms of the total sown area of farm crops [46,47]. Due to differences in natural environments and irrigation conditions, large differences also exist in the planting structure of various regions. The adjustment of crop planting structure should be one 
important method used to optimize water resource allocation [48]. However, this was not within the scope of this study. In terms of input-output indicators, total indicators were still selected. Fourth, agricultural water utilization is expressed as the total agricultural water of each province. With the improvement in agricultural irrigation methods and technologies, the total agricultural water use has an important impact on the improvement in agricultural water use efficiency (Zhu, 2016) [49]. Moreover, the water consumption in agricultural production did not show a significant decrease from 277.2 to 273.2 billion $\mathrm{m}^{3}$ in the last 10 years, so the water efficiency also depends on other input-output indicators. Fifth, agricultural chemical fertilizers are expressed as the amount of agricultural chemical fertilizers, as the most important means to increase agricultural production in China. Considering the pollution discharge, pesticides are no longer used as input indicators here.

The relevant data were derived from the China Statistical Yearbook of 2007-2017, the statistical yearbooks of various provinces, and relevant statistical bulletins. The water utilization efficiency in the Yellow River Basin was estimated by using Frontier 4.1 software with the stochastic frontier analysis model (SFA). Firstly, the software uses the least squares method to make corresponding efficiency estimates for the model. If technical inefficiency occurs, the program further iterates with the grid search method based on the parameter values estimated by the least squares. Then, the likelihood value is used to estimate the final value. The analysis results are provided in Table 1, and depicted in Figure 3 in some key years.

Table 1. Measurements of agricultural water utilization efficiency in the Yellow River Basin.

\begin{tabular}{cccccccccccc}
\hline Province & $\mathbf{2 0 0 7}$ & $\mathbf{2 0 0 8}$ & $\mathbf{2 0 0 9}$ & $\mathbf{2 0 1 0}$ & $\mathbf{2 0 1 1}$ & $\mathbf{2 0 1 2}$ & $\mathbf{2 0 1 3}$ & $\mathbf{2 0 1 4}$ & $\mathbf{2 0 1 5}$ & $\mathbf{2 0 1 6}$ & $\mathbf{2 0 1 7}$ \\
\hline Shanxi & 0.08 & 0.16 & 0.23 & 0.30 & 0.36 & 0.41 & 0.46 & 0.51 & 0.55 & 0.59 & 0.62 \\
Inner & 0.13 & 0.21 & 0.27 & 0.34 & 0.39 & 0.44 & 0.49 & 0.53 & 0.57 & 0.61 & 0.64 \\
Mongolia & & & & & & & \\
Shandong & 0.63 & 0.66 & 0.69 & 0.72 & 0.74 & 0.76 & 0.78 & 0.80 & 0.82 & 0.83 & 0.85 \\
Henan & 0.50 & 0.54 & 0.58 & 0.62 & 0.65 & 0.68 & 0.71 & 0.73 & 0.75 & 0.77 & 0.79 \\
Sichuan & 0.97 & 0.98 & 0.98 & 0.98 & 0.98 & 0.98 & 0.99 & 0.99 & 0.99 & 0.99 & 0.99 \\
Shaanxi & 0.74 & 0.76 & 0.78 & 0.80 & 0.82 & 0.83 & 0.85 & 0.86 & 0.87 & 0.88 & 0.89 \\
Gansu & 0.21 & 0.28 & 0.34 & 0.39 & 0.44 & 0.49 & 0.54 & 0.57 & 0.61 & 0.64 & 0.67 \\
Qinghai & 0.14 & 0.21 & 0.28 & 0.34 & 0.39 & 0.45 & 0.49 & 0.54 & 0.58 & 0.61 & 0.64 \\
Ningxia & 0.01 & 0.02 & 0.07 & 0.15 & 0.22 & 0.29 & 0.35 & 0.40 & 0.45 & 0.50 & 0.54 \\
mean & 0.37 & 0.42 & 0.47 & 0.51 & 0.56 & 0.59 & 0.63 & 0.66 & 0.69 & 0.71 & 0.74 \\
value & 0.98 & 0.79 & 0.64 & 0.53 & 0.46 & 0.39 & 0.34 & 0.30 & 0.26 & 0.23 & 0.20 \\
CV & & & & & & & & & & &
\end{tabular}
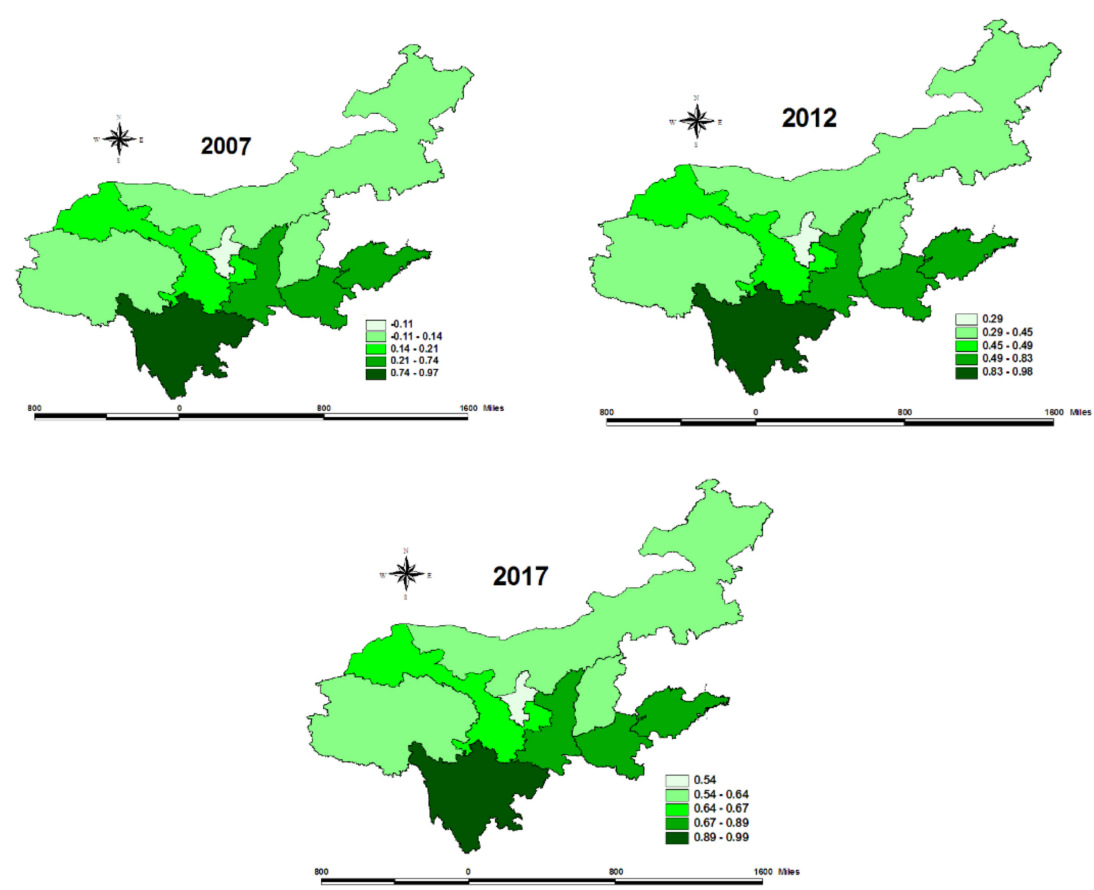

Figure 3. The graduated color figures of agricultural water efficiency in 2007, 2012, and 2017. 


\subsection{Estimation Results of the Dynamic Panel Model}

The driving factors for high-quality urbanization development to improve the efficiency of agricultural water utilization are mainly considered from the aspects of population urbanization, economic urbanization, and balanced urbanization as the index of urbanization level. We also selected technology innovation, per capita water availability, annual precipitation, the crop planting ratio, and rice planting ratio as control variables. Dhake (2016) and Zuo (2019) selected indicators such as the age of the head of the household, the educational level of the household, and the characteristics of the land, which were based on the micro-data of the farmers' producers to study water use efficiency $[50,51]$. However, we focused on the input and output of water efficiency at the macro-provincial level with double-control action. Thus, micro-level indicators were not considered. Many experts have also selected many individual variables from the perspective of micro-farmers to examine the difference in irrigation water efficiency, which is different from the research theme of this study.

We selected some key variables from the different aspects of urbanization development. First, the proportion of urban residents in each province was used to represent the standard of population urbanization, which represented the concentration of the population in urban areas. The indicators were selected from the level of the resident population for accurate measurement to reflect the transfer of the rural surplus labor force [52]. Second, the proportion of the tertiary industry in GDP was selected as the economic urbanization, which can better reflect the development and evolution of the industrial structure than the secondary industry [53]. In the process of economic development, agriculture was transformed into industries, and then industry was transformed into services. The higher the ratio, the more reasonable it became. Third, the urban primary ratio, that is, the ratio of the first city to the second city in terms of urban population as the balanced urbanization, represents the balance of the level of urbanization development in the region [54]. The urban primary ratio played different roles in different stages of urbanization. Many experts have proposed the concepts of social urbanization, urban-rural integration, green urbanization, and so forth. However, we only selected some key variables that would affect the agricultural water efficiency from a theoretical perspective.

To ensure the accuracy of model estimation results, we selected some key control variables. First, the number of three kinds of patents granted per 10,000 people was adopted to represent the level of technological innovation. The improvement in agricultural water efficiency also depends on the continuous improvement of water-saving and emission-reduction technologies. The indexes of R\&D investment and high-tech industries were also adopted in some other papers [55], but we argue that patent invention better explains the products of technical innovation. Second, the ratio of the total water resources of each province to the total population of each province, taking the natural logarithm, was used to indicate per capita water availability, which measures the abundance of water resources in each region. This index can verify the curse of resources. Third, the annual precipitation of each region, taking the natural logarithm, was used to measure the abundance of water resources, which also implies some other natural conditions. Fourth, the ratio of crop planting area to the total planting area was used as the crop ratio. Generally, cash crops produce greater economic profits. Finally, the ratio of regional rice planting area to the total planting area was selected to measure the demand of water resources in each region. Rice production requires more water compared to dryland crops. The most relevant data were obtained from the Statistical Yearbooks of China and the Statistical Yearbooks of the provinces, as well as from the Water Resources Yearbooks of China in the period of 2007-2017. The driving factors were estimated by Stata 15.1 software, and the results are shown in Table 2. 
Table 2. Dynamic panel model estimation of agricultural water utilization efficiency in the Yellow River Basin.

\begin{tabular}{|c|c|c|c|c|c|c|c|c|}
\hline Variables & $\begin{array}{l}\text { Regression } \\
\text { Coefficient }\end{array}$ & SD & $\begin{array}{c}\mathrm{Z} \\
\text { Statistics }\end{array}$ & $P$ Value & $\begin{array}{l}\text { Regression } \\
\text { Coefficient }\end{array}$ & SD & $\begin{array}{c}\mathrm{Z} \\
\text { Statistics }\end{array}$ & P Value \\
\hline Estimation Type & \multicolumn{4}{|c|}{ Difference GMM } & \multicolumn{4}{|c|}{ System GMM } \\
\hline Water utilization & 0.9206 & 0.0104 & 88.69 & 0.000 & 0.9197 & 0.0073 & 126.46 & 0.000 \\
\hline Population urbanization & $-0.0665^{*}$ & 0.0356 & -1.87 & 0.062 & $-\underset{* *}{-0.0566}$ & 0.0262 & -2.16 & 0.031 \\
\hline Economic urbanization & -0.0236 & 0.0085 & -2.77 & 0.006 & -0.0191 & 0.0091 & -2.08 & 0.037 \\
\hline Balanced urbanization & $-0.0021 *$ & 0.0012 & -1.74 & 0.083 & -0.0007 & 0.0011 & -0.65 & 0.517 \\
\hline Technology innovation & $0.0010^{* * *}$ & 0.0003 & 3.71 & 0.000 & $0.0010 * *$ & 0.0003 & 3.41 & 0.001 \\
\hline Per capita water availability & 0.0022 & 0.0041 & 0.53 & 0.595 & 0.0035 & 0.0039 & 0.90 & 0.366 \\
\hline Precipitation & 0.0057 & 0.0086 & 0.66 & 0.509 & 0.0041 & 0.0081 & 0.51 & 0.611 \\
\hline Crop planting ratio & $-\underset{* * *}{0.0315}$ & 0.0043 & -7.40 & 0.000 & $-\underset{* * *}{-0.0349}$ & 0.0043 & -8.21 & 0.000 \\
\hline Rice planting ratio & -0.4635 & 0.1801 & -2.57 & 0.010 & -0.1595 & 0.1100 & -1.45 & 0.147 \\
\hline Constant & 0.1163 & 0.0370 & 3.14 & 0.002 & 0.0974 & 0.0401 & 2.43 & 0.015 \\
\hline
\end{tabular}

\section{Results and Discussion}

\subsection{Law of Agricultural Water Utilization Efficiency}

The agricultural water utilization efficiency values of each province in the Yellow River Basin from 2007 to 2017 are shown in Table 1. From the perspective of the overall dynamic development trend, the agricultural water utilization efficiency steadily increased, and the agricultural water utilization efficiency of each province maintained an upward trend year by year. The average agricultural water efficiency increased from 0.37 in 2007 to 0.74 in 2017, indicating increasing attention paid by the local government to the protection of the natural environment, energy saving, and emission reduction by the local government. The discharge of agricultural wastewater pollution was in control, which is required for the further development of industry and agriculture [56]. In particular, the rate of increase in agricultural water utilization efficiency during 2007-2011 was relatively obvious, but the rate slowed between 2015 and 2016. In addition, the Ningxia and Shanxi provinces had the fastest average annual growth rates, which are inseparable from the local government's water resources management system policies and industrial development $[57,58]$. However, Li (2018) pointed out that the comprehensive water efficiency in China still has great water-saving potential, on the basis of the investigation of pure technical efficiency and scale efficiency of agricultural water [59]. In general, the Yellow River Basin has low water utilization efficiency with the characteristics of less water and more sand, which needs to be the focus of additional efforts to improve agricultural water use efficiency [60].

From the perspective of spatial disparity, the agricultural water utilization efficiency in Sichuan, Shaanxi, and Shandong was relatively high from 2007 to 2017, higher than the average agricultural water utilization efficiency. The agricultural water use efficiency in Qinghai and Inner Mongolia was lower than the average value of the whole basin, and were almost the same as each other. Basically, the agricultural water use efficiency in the eastern part of the Yellow River Basin was higher, whereas the western part was lower, except for Sichuan province, during the whole period. Since most of Sichuan belongs to the Yangtze River Basin and is located in the southern region of China, the crop planting ratio differs from other regions, enabling more efficient agricultural water utilization. The agricultural water efficiency of Ningxia was relatively low and the highest value was only 0.54 in 2017 . This shows that the large amount of available water resources was not used reasonably or to its full potential in agricultural production activities; thus, the water-savings potential is large. The reason is related to the level of regional economic development and agricultural irrigation technology. The relative lack of water resources in the region, the ecological environment, and the harsh climate also reduce the agricultural water use efficiency to some extent [61-63]. In addition, the large-scale flood irrigation as 
an irrigation method formed in the history of Ningxia resulted in a large amount of water resources being lost during evaporation and leakage. Coupled with serious channel leakage and incomplete management, as well as various other factors, serious waste of freshwater resources and ecological environment damage are huge problems [64]. To meet the requirements of agriculture and other sectors of the national economy, excessive groundwater extraction is also one of the main reasons [65]. The exploitation and utilization of groundwater resources in the northern plains of China have mostly approached or exceeded their limits, and the amount of groundwater exploitation in the plains of the Yellow River Basin has already reached 92\%.

From the perspective of inter-regional convergence, the variation coefficient is the ratio of the standard deviation to the average value, which is used to measure the degree of dispersion and spatial difference of inter-regional efficiency values. The variation coefficient of agricultural water utilization in the Yellow River Basin showed an overall downward trend from 0.98 in 2007 to 0.20 in 2017. Agricultural water utilization has converged during the past 11 years. The provinces showed a synchronous change trend, the differences between regions shrank, and the internal differences converged. Moreover, the high-quality coordinated development of regions will further promote the convergence effect. In particular, the convergence rate was comparatively more rapid in the four years from 2007 to 2010, which is consistent with the environmental Kuznets curve, indicating that economic development is the ultimate solution to resource and environmental problems [66,67]. Ding (2019) found a convergence trend when studying the overall water use and industrial water use efficiency of the Yangtze River Economic Belt. He opined that this convergence is due to innovation spillovers in water-saving technologies and the spatial flow of related talents $[68,69]$. The upper reaches of the Yellow River Basin also converged relatively quickly, but this was related to the large-scale development of the northwestern region and the strategy for the economic rise of the central region. The water utilization efficiency of agriculture in the upper reaches of the Yellow River Basin was comparatively lower, and the problems of extreme water shortage and groundwater depletion in the lower reaches still need to be resolved.

\subsection{Factors Driving Agricultural Water Utilization Efficiency}

The estimated results of the dynamic panel regression model for agricultural water utilization efficiency in the Yellow River Basin can be seen in Table 2. The results revealed that the factors of population urbanization, economic urbanization, technology innovation, crop planting ratio, and rice planting ratio significantly affected agricultural water utilization efficiency. The results in the two models were basically the same. The per capita water availability and precipitation did not pass the significance test in the difference GMM and system GMM estimates, and the balanced urbanization failed to pass the system GMM significance test. According to the estimation results, the estimation of the difference-GMM is more accurate and more consistent with the expected results, so the results of the difference-GMM were selected for the following interpretation (Zhang, 2017) [70].

The population urbanization factor was significantly negatively related to agricultural water utilization efficiency. From 2007 to 2017, the urbanized population in the Yellow River Basin increased from 15.054 million to 22.874 million, and the population urbanization rate of most cities increased by more than $13 \%$. With the decline in the proportion of the agricultural population, agricultural water utilization also declined. We found a negative correlation between the urbanization rate of the population and the proportion of agricultural water utilization. The development of urbanization has caused a change in the population structure. The rural labor force has gradually moved to the city and from agricultural industry to the secondary and tertiary industries. As income from urban job opportunities is much higher than that from food production, that means farmers' enthusiasm for production decreases, the agricultural irrigation rate decreases, and part of the farmland is deserted [71]. $\mathrm{Li}$ (2017) and Zhang (2020) reported that most of the transfer of labor was relatively young and high-quality rural labor. This kind of transfer affects the use of agricultural production technology, which is not conducive to improvements in agricultural water efficiency [72,73]. The increase in 
urban populations and the expansion of the secondary and tertiary industries led to an increase in the proportion of urban domestic water. Simultaneously, the demand for secondary and tertiary water also increased, which led to a decline in the proportion of agricultural water in total water utilization [74]. More studies suggested that the transfer of labor is caused by the large amount of labor released by the advancement of agricultural technology. The substitution effect will increase agricultural labor productivity, while promoting agricultural modernization (Zhang et al., 2017; Lu, 2019) [75,76].

From the perspective of economic urbanization, a negative correlation was identified between economic urbanization and agricultural water utilization efficiency at the $1 \%$ level. We chose the proportion of the output value of the tertiary industry as a measurement index, which can better reflect the conditions of industrial development. With the development of production activities, the non-agricultural industry is continually changing. New-type urbanization is accompanied by economic growth, also including the accumulation of production factors in cities caused by industrial structure upgrades, and the concentration of non-agricultural investment, technology, and production capacity [77]. The development of productive services has scarcely provided substantial positive assistance to agricultural development, has crowded out the space for agricultural development, and has even caused the pollution of water resources, as well as considerable damage to the environment, which inevitably leads to the slow development of agriculture and a lack of attention to the development of the agricultural industry. In theory, the development of the secondary industry can directly nurture agriculture, providing material equipment and technical support for agricultural ecological transformation and water-saving irrigation (Jiang, 2017) [78]. However, Hao (2019) stated that the overall efficiency is low, and related technologies that directly serve green agriculture and water-saving agriculture are lacking [79]. Yang (2019) verified that, for resource-based cities in China, the increase in industrial productivity has more of a siphon effect on agriculture [80]. However, Liu (2017) found that the impact of the industrial sector on the agricultural sector has changed from siphoning to nurturing [81].

From the perspective of balanced urbanization, the urban primary index is significantly negatively related to agricultural water utilization efficiency. The development of a disequilibrium in urbanization is not conducive to the overall improvement of regional agricultural water utilization efficiency. The average urban primary index in the Yellow River Basin dropped from 2.37 to 2.22 from 2007 to 2017, and the decline in Qinghai province was the most obvious, from 4.93 to 2.7. Although the index scores of most of the provinces consistently exceeded 2.5, the index score of Sichuan province always exceeded 4.2. The unbalanced urbanization structure of "one city dominates" affects the economic impacts of cities. In addition, the emergence of megacities will crowd out resources as technological innovation and environmental governance in other cities to some extent, which is not beneficial to the improvement of overall agricultural water efficiency. The expansion of central cities and the accumulation of the population in central cities negatively affects the development of water-saving technologies and green economies [82-84]. Thus, too scattered or overly concentrated urban populations will lead to loss of efficiency and slow economic growth [85]. Chen (2017) proved that no clear distinction exists between good and bad for the urban primary ratio, but it needs to be consistent with the stage of economic development and has to have a reasonable upper limit. The positive effect is more significant in less developed regions [86]. Jin (2017) proposed that too high a concentration inhibits the development of the surrounding urban and rural areas. For primary urban development, the simple expansion of the urban population should be changed, and efficient use of resources and cutting-edge technological innovation should be pursued [87].

From the perspective of other control variables of agricultural water utilization efficiency, the level of technological innovation had a significantly positive effect on the agricultural water utilization efficiency at the $1 \%$ level in the difference-GMM model. Scientific and technological innovation plays an important role in the use of water resources, especially in areas with high agricultural water consumption, such as Shandong and Henan. In provinces such as Qinghai, which are dominated by animal husbandry, advances in agricultural technology have had a significant impact on the 
improvement of agricultural water utilization efficiency. The innovation of agricultural production technology and the improvement of policies related to the use of agricultural water resources will benefit the overall agricultural and irrigation output rates. The estimation results of the Diff-GMM model revealed that the crop planting structure and agricultural water utilization efficiency are significantly negatively correlated at the $1 \%$ level. Basically, the higher the proportion of crops planted, the greater the amount of water used; thus, agricultural water utilization efficiency will decrease [88-90]. In terms of rice, as a water-intensive crop with large water consumption but low output [91], the negative effect of the rice planting ratio on agricultural water use efficiency is much larger than that of the crop planting ratio. Annual precipitation and per capita water availability, as the two indicators of water resources endowment, did not pass the significance test. The impact of annual precipitation on agricultural water use efficiency is more complicated. In areas with sufficient rainfall, farmers' awareness of water saving is weak. Thus, the wasteful use of water resources will reduce agricultural water use efficiency. The agricultural water resources are abundant in areas with sufficient rainfall, which is beneficial to the growth of crops, thus improving agricultural incomes.

\section{Conclusions}

Exploring the influence of urbanization development characteristics on agricultural water utilization efficiency has practical significance for promoting high-quality development and agricultural water use efficiency. In the study, we used a stochastic frontier analysis model to scientifically measure agricultural water utilization efficiency in the provinces of the Yellow River Basin from 2007 to 2017. The results indicated that the overall efficiency of agricultural water utilization maintained a steady upward trend over the 10-year period. During the research period, water use efficiency was higher in the eastern region and lower in the western region. Particularly from 2007 to 2011, each province had a high annual growth rate, and the growth rate then flattened over the next five years. The estimation results showed that the developed provinces generally had higher water use efficiency; thus, economic development is a fundamental method to solve the problem of water resource efficiency and water pollution. The variation coefficient of water utilization efficiency in the Yellow River Basin experienced an overall downward trend, indicating a significant spatial spillover of water utilization efficiency. Agricultural water use efficiency has continued to converge during the study period, especially for the upper reaches of the basin. The provinces showed a synchronous change trend, the differences between regions shrunk, and the internal differences converged. In addition, the high-quality coordinated development of provinces proposed by the central government will further promote this convergence effect in future years.

We then used the dynamic panel difference GMM model and system GMM models to estimate the drivers of agricultural water efficiency. Population urbanization, economic urbanization, and balanced urbanization were selected as the core variables. We also selected technological innovation, natural resources, planting structure, and some other variables as control variables. The results demonstrated that the population urbanization negatively affected agricultural water utilization efficiency. In the process of urbanization, large numbers of skilled youth leave the countryside, whereas the old and weak remain. The imbalanced development of urbanization has had a negative impact on agricultural water use efficiency. The emergence of megacities will, to some extent, squeeze more resources from small cities and rural areas, such as technological innovation and environmental governance, reducing those available to agricultural areas, which is not conducive to improving water efficiency. Economic urbanization is significantly negatively related to agricultural water use efficiency. Not only does the development of productive services not provide substantial positive assistance to agricultural development, it also occupies the space for agricultural development, resulting in slow agricultural development. Technological innovation plays a positive role in the use of agricultural water resources. The higher the proportion of crops planted, the higher the amount of water used, and the lower the efficiency of agricultural water utilization. 
Based on the research results above, to further improve the efficiency of agricultural water utilization in the Yellow River Basin and to promote high-quality urbanization, the following suggestions are proposed. First, the quality of urbanization should be comprehensively improved, and agricultural technical talents should be cultivated, reasonably guiding the transfer of surplus labor. Second, the government should strengthen the deep integration of the service and agricultural industries. Production technology, market consulting, and services should be provided for agricultural development. Third, the government should focus on promoting the industrialization of nearby cities, as well as that of small- and medium-sized towns to retain more talent in the countryside. Fourth, the government should apply effective measures to accelerate the popularization and innovation of water-saving technologies and the promotion of water resource recycling. Fifth, the government should strictly supervise water resource utilization, as well as advocate the concepts and modes of water conservation. Efforts should be made to strengthen the dual role of economic leverage and administrative means. Sixth, the agricultural planting structure should be optimized, and dry farming should be actively developed. The local government should promote the development of agricultural deep processing and enhance agricultural added value.

Author Contributions: Conceptualization, X.Z. and X.D.; methodology, X.Z.; software, X.Z.; validation, X.Z., X.D. and Y.K.; formal analysis, X.Z.; investigation, X.Z.; resources, X.Z.; data curation, X.Z.; writing-original draft preparation, X.X.; writing-review and editing, X.Z.; visualization, X.D.; supervision, Y.K.; project administration, Y.K.; funding acquisition, X.D. All authors have read and agreed to the published version of the manuscript.

Funding: This research was supported by Social Science Foundation of Jiangsu Province (18GLC002), National Natural Science Foundation of China (71603071), and the National Social Science Foundation of China (16CJY018).

Conflicts of Interest: The authors declare no conflict of interest.

\section{References}

1. Yellow River Conservancy Commission of MWR. Yellow River Resources Bulletin. 2018. Available online: http://www.yrcc.gov.cn/other/hhgb/ (accessed on 30 March 2020).

2. Nafyad, S.K.; Shankar, K. Groundwater Quality Assessment using Water Quality Index and GIS Technique in Modjo River Basin, Central Ethiopia. J. Afr. Earth Sci. 2018, 147, 300-311.

3. Liu, Y.Y.; Mao, D.H. Integrated Assessment of Water Quality Characteristics and Ecological Compensation in the Xiangjiang River, South-central China. Ecol. Indic. 2020, 110, 105922. [CrossRef]

4. Liu, H.J.; Qiao, L.C.; Sun, S.H. Spatial Distribution and Dynamic Change of Water Use Efficiency in the Yellow River Basin. Resour. Sci. 2020, 42, 57-68.

5. Xi, J.P. Speech at the Symposium on Ecological Protection and High-Quality Development of the Yellow River Basin. Water Resour. Dev. Manag. 2019, 11,1-4.

6. Li, S.X.; Cheng, J.H.; Wu, Q.S. Regional Difference of the Efficiency of Water Usage in China. China Popul. Resour. Environ. 2008, 18, 215-220.

7. Liao, H.C.; Dong, Y.M. Utilization Efficiency of Water Resources in 12 Western Provinces of china Based on the DEA and Malmquist TFP Index. Resour. Sci. 2011, 33, 273-279.

8. Karagiannis, G.; Tzouvelekas, V.; Xepapadeas, A. Measuring Irrigation Water Efficiency with a Stochastic Production Frontier. Environ. Resour. Econ. 2003, 26, 57-72. [CrossRef]

9. Ding, X.H.; He, J.H.; Wang, L.Y. Inter-provincial Water Resources Utilization Efficiency and Its Driving Factors Considering Undesirable Outputs: Based on SE-SBM and Tobit model. China Popul. Resour. Environ. 2018, 28, 157-164.

10. Wang, M.; Sun, C.Z.; Wang, X.L. Analysis of the Water-Energy Coupling Efficiency in China: Based on the Three-Stage SBM-DEA Model with Undesirable Outputs. Water 2019, 11, 632. [CrossRef]

11. Sun, C.Z.; Ma, Q.F.; Zhao, L.S. Green Efficiency Changes for Water Resources in China Based on SBM-Malmquist Model. Resour. Sci. 2018, 40, 993-1005.

12. Tong, J.P.; Ma, J.F.; Wang, H.M.; Qin, T.; Wang, Q. Research on Agricultural Total-factor Water Use Efficiency and Its Influencing Factors in China. Econ. Probl. 2014, 6, 101-106.

13. Ma, H.L.; Shi, C.L.; Chou, N.T. China's Water utilization efficiency: An analysis with environmental considerations. Sustainability 2016, 8, 516. [CrossRef] 
14. Wei, L.L.; Li, W.M. Agricultural Water Use Efficiency and Influencing Factors in Xinjiang. J. Xinjiang Univ. (Philos. Humanit. Soc. Sci.) 2014, 42, 7-10.

15. Zhao, J.; Meng, H.; Gong, J. Measurement of Total Factor Agricultural Water Efficiency and Analysis of Influential Factor in Jing-Jin-Ji Area. J. China Agric. Univ. 2017, 22, 76-84.

16. Xu, L.; Huang, Y. Measurement of Irrigation Water Efficiency and Analysis of Influential Factors: An Empirical Study of Mengcheng County in Anhui Province. Resour. Sci. 2012, 34, 105-113.

17. Ma, J.F.; Wang, H.M.; Tong, J.P. Research on Spatial Effects of Technological Progress and Efficiency Catch-up on Agricultural Water Use Efficiency. China Popul. Resour. Environ. 2018, 28, 36-45.

18. Yang, J. The Impact of China's New Urbanization Development Level on Agricultural Industry Structure. Econ. Surv. 2016, 33, 84-89.

19. Yang, S.H.; Song, T.Q.; Chen, H.J. Impact of Industrialization and Urbanization on Construction of Agricultural Modernization. China Popul. Resour. Environ. 2012, 22, 398-403.

20. He, J.L. Impact of Urbanization on Agricultural Sustainable Development and Its Policy Tropism. Res. Agric. Mod. 2002, 3, 208-210.

21. Zhang, X.L.; Wu, Y.Z.; Skitmore, M.; Jiang, S.J. Sustainable Infrastructure Projects in Balancing Urban-rural Development: Towards the Goal of Efficiency and Equity. J. Clean. Prod. 2015, 109, 445-454. [CrossRef]

22. Sabet, N.S.; Azharianfar, S. Urban-rural Reciprocal Interaction Potential to Develop Weekly Markets and Regional Development in Iran. Habitat Int. 2017, 61, 31-44. [CrossRef]

23. Charter, H.O.; Ireri, D. Linkage of California-Arizona Input-Output Models to Analyze Water Transfer Patterns; University of California: Berkeley, CA, USA, 1968.

24. Christian, S.J.; Cooley, H.; Gleick, P.H. Potential Water Savings Associated with Agricultural Water Efficiency Improvements: A Case Study of California. Water Policy 2012, 14, 194-213. [CrossRef]

25. Portnov, B.A.; Safriel, U.N. Combating Desertification in the Negev: Dryland Agriculture vs. Dryland Urbanization. J. Arid Environ. 2004, 56, 659-680. [CrossRef]

26. Feng, H.Y.; Shi, P.J.; Zhou, W.X.; Chen, J.Y.; Zhang, X.B. Threshold Analysis of Urbanization with the Constraint of "Three Red Lines" on Water Resources Management: A case study of Zhangye City. J. Nat. Resour. 2018, 33, 287-301.

27. Jin, W.; Zhang, H.Q.; Zhang, H.B.; Kong, W.; Mao, G.X.; Zhang, C.J.; Yan, X. The Influence of Population Structural Change on Water Consumption in Urbanization. Resour. Sci. 2018, 40, 784-796.

28. Wang, Z.Q.; Yang, J.; Deng, X.Z.; Lan, X. Optimal Water Resources Allocation under the Constraint of Land Use in the Heihe river Basin of China. Sustainability 2015, 7, 1558-1575. [CrossRef]

29. Wang, J.H.; He, F. Cognitive Analysis of Dual-control Action of Total Water Consumption and Intensity in View of Bearing Capacity. China Water Resour. 2016, 23, 34-40.

30. Yan, T.T.; Liu, D.X.; Luo, L.; Fan, L. Analysis and Reflection on the Implementation of the Dual Action of Total Water Consumption and Intensity. Water Resour. Dev. Res. 2017, 17, 89-93.

31. Aigner, D.; Lovell, C.K.; Schmidt, P. Formulation and Estimation of Stochastic Frontier Function Models. J. Econom. 1977, 6, 21-37. [CrossRef]

32. Meeusen, W.; Van Den Broeck, J. Efficiency Estimation from Cobb-Douglas Production Functions with Composed Error. Int. Econ. Rev. 1977, 18, 435-444. [CrossRef]

33. Kumbhakar, S.C.; Lovell, C.K. Stochastic Frontier Analysis; Cambridge University Press: Cambridge, UK, 2000.

34. Lei, Y.T.; Huang, L.P. Regional Differences in Industrial Water Consumption Efficiency and Its Influencing Factors for China's Major Industrial Provinces: A Study of Provincial Panel Data Based on SFA. China Soft Sci. 2015, 4, 155-164.

35. Wang, X.Y. Comparative Study of Irrigation Water Efficiency in China's Provinces Based on DEA and SFA Methods. Stat. Decis. 2010, 8, 44-47.

36. Zhang, X.; Shi, X. Comparison on Multi-level Model and Static Panel Data Model. Stat. Inf. Forum 2010, 25, $22-26$.

37. Holtz-Eakin, D.; Newey, W.; Rosen, H.S. Estimating Vector Autoregressions with Panel Data. Econometrica 1988, 56, 1371-1395. [CrossRef]

38. Blundell, R.; Bond, S. Initial Conditions and Moment Restrictions in Dynamic Panel Data Models. J. Econom. 1998, 87, 115-143. [CrossRef]

39. Judson, R.A.; Owen, A.L. Estimating Dynamic Panel Data Models: A Guide for Macroeconomists. Econ. Lett. 1999, 65, 9-15. [CrossRef] 
40. Arellano, M.; Bond, S. Some Tests of Specification for Panel Data: Monte Carlo Evidence and an Application to Employment Equations. Rev. Econ. Stud. 1991, 58, 277-297. [CrossRef]

41. Bouayad-Agha, S.; Vedrine, L. Estimation Strategies for a Spatial Dynamic Panel Using GMM-A New Approach to the Convergence Issue of European Regions. Spat. Econ. Anal. 2010, 5, 205-227. [CrossRef]

42. Darku, A.B. The Impact of Trade Liberalization and the Fiscal Equalization Transfer Policy on Provincial Income Disparities in Canada: An Application of GMM Estimation. Appl. Econ. 2011, 43, 1679-1689. [CrossRef]

43. Hu, J.; Shang, Y.R.; Shi, X.R.; Hu, Q.H. Adjustment of Crop Planting Structure Considering Optimal Allocation of Water Resources-A Case Study of Xingtai City, Hebei Province. Water Sav. Irrig. 2016, 1, 76-80.

44. Song, Y.; Cao, Y.P. The Research on Influencing Factors and Dynamic Coupling of New Ecological Urbanization Based on GMM. Ecol. Econ. 2019, 35, 67-72.

45. Ma, J.F.; Qin, T.; Tong, J.P.; Sun, D.Y. Industrial Agglomeration, Urban Agglomeration and Water Consumption. Soft Sci. 2018, 32, 95-99.

46. Cao, K.H.; Birchenall, J.A. Agricultural Productivity, Structural Change, and Economic Growth in Post-reform China. J. Dev. Econ. 2013, 104, 165-180. [CrossRef]

47. Wu, S.L. The Contribution of Agricultural Labor Migration to Economic Growth in China. Econ. Res. J. 2016, 51, 97-110.

48. Lv, Y.J.; Kong, L.C.; Li, Y. Measurement of Coupling Coordination Degree between Urbanization and Ecological Environment in China. Urban Probl. 2019, 12, 13-22.

49. Zhu, M.L.; Liu, J. Study on the Evaluation Index System of Agricultural Efficiency and Water Saving in the Arid Regions of Northwest China. Water Sav. Irrig. 2016, 2, 95-100.

50. Dhake, A.V.; Subramaniam, V.R.; Desarda, G.I.; Borole, V. Enhancing Water Use Efficiency in Onion Bulb Production: A Farmer-centric Approach. Int. J. Innov. Hortic. 2016, 5, 94-97.

51. Zuo, Z.Y. Farmers' Irrigation Technology Choice and Collective Action under Water Resources Constraints-Based on Micro-data of Farmers in North China Groundwater Over-exploitation Area. Rural Econ. 2019, 7, 64-71.

52. Zhang, Y.; Song, L.; Zhu, X.B. Research on the Efficiency of China's Regional Patent Structure from a Two-Stage Perspective. J. Intell. 2020, 1, 201-207.

53. Zhou, Y.; Kong, Y.; Sha, J.; Wang, H.K. The Role of Industrial Structure Upgrades in Eco-efficiency Evolution: Spatial Correlation and Spillover Effects. Sci. Total Environ. 2019, 687, 1327-1336. [CrossRef]

54. Liu, C.L.; Wang, T.; Guo, Q.B. Factors Aggregating and the Regional Differences among China Urban Agglomerations. Sustainability 2018, 10, 4179. [CrossRef]

55. Song, X.; Zhou, Y.; Wei, J. How do Economic Openness and R\&D Investment Affect Green Economic Growth? Evidence from China. Resour. Conserv. Recycl. 2019, 146, 405-415.

56. Shang, Y.Z.; Wang, J.H.; Liu, J.H.; Jiang, D.; Zhai, J.Q.; Jiang, S. Suitability Analysis of China's Energy Development Strategy in the Context of Water Resource Management. Energy 2016, 96, 286-293. [CrossRef]

57. Yang, L.; Ouyang, H.; Fang, K.N.; Ye, L.L.; Zhang, J. Evaluation of Regional Environmental Efficiencies in China Based on Super-efficiency-DEA. Ecol. Indic. 2015, 51, 13-19. [CrossRef]

58. Tian, Y.H.; Liu, Y.Q.; Jin, J.J. Effect of Irrigation Schemes on Forage Yield, Water Use Efficiency, and Nutrients in Artificial Grassland under Arid Conditions. Sustainability 2017, 9, 2035. [CrossRef]

59. Li, J.; Xu, D.J. Agricultural Water Utilization Efficiency and Its Influencing Factors in China: Based on MinDW Model. J. Environ. Econ. 2018, 3, 56-74.

60. Guan, X.J.; Liang, S.X.; Meng, Y. Evaluation of Water Resources Comprehensive Utilization Efficiency in the Yellow River Basin. Water Sci. Technol. Water Supply 2016, 16, 1561-1570. [CrossRef]

61. Kang, S.Z.; Hao, X.M.; Du, T.S.; Tong, L.; Su, X.L.; Lu, H.M.; Li, X.L.; Huo, Z.L.; Li, S.; Ding, R.S. Improving Agricultural Water Productivity to Ensure Food Security in China under Changing Environment: From Research to Practice. Agric. Water Manag. 2017, 179, 2-17. [CrossRef]

62. Valipour, M. Land Use Policy and Agricultural Water Management of the Previous Half of Century in Africa. Appl. Water Sci. 2015, 5, 367-395. [CrossRef]

63. Wang, F.T.; Yu, C.; Xiong, L.C.; Chang, Y. How can agricultural water use efficiency be promoted in China? A spatial temporal analysis. Resour. Conserv. Recycl. 2019, 145, 411-418. [CrossRef] 
64. Liu, Y.; Hu, X.H.; Zhang, Q.; Zheng, M.B. Improving Agricultural Water Use efficiency: A Quantitative Study of Zhangye City Using the Static CGE Model with a CES Water-Land Resources Account. Sustainability 2017, 9, 308. [CrossRef]

65. Zhou, L.; Mekonnen, M.M.; Hoekstra, A.Y.; Wda, Y. Inter- and Intra-annual Variation of Water Footprint of Crops and Blue Water Scarcity in the Yellow River Basin (1961-2009). Adv. Water Resour. 2016, 87, $29-41$. [CrossRef]

66. Apergis, N.; Ozturk, I. Testing Environmental Kuznets Curve Hypothesis in Asian Countries. Ecol. Indic. 2015, 52, 16-22. [CrossRef]

67. Ridzuan, S. Inequality and the Environmental Kuznets curve. J. Clean. Prod. 2019, 228, 1472-1481. [CrossRef]

68. Ding, X.H.; Fu, Z.; Jia, H.W. Study on Urbanization Level, Urban Primacy and Industrial Water Utilization Efficiency in the Yangtze River Economic Belt. Sustainability 2019, 11, 6571. [CrossRef]

69. Ding, X.H.; Tang, N.; He, J.H. The Threshold Effect of Environmental Regulation, FDI Agglomeration and Water Use Efficiency under "Double Control Actions"-An Empirical Test Based on Yangtze River Economic Belt. Water 2019, 11, 452. [CrossRef]

70. Zhang, Z.Q. A Comparative Study on Dynamic Panel Parameter Estimation. Stat. Res. 2017, 23, $108-119$.

71. Shao, W.W.; Liu, H.Z.; Zhou, Z.H.; Cao, X.L. Influencing Factors and Countermeasure for Agricultural Water during Urbanization and Industrialization in Northeast China. J. Econ. Water Resour. 2015, 33, 1-3.

72. Li, S.M.; Yin, X.W. Analysis of the impact of Chinese Rural Labor Migration on Agricultural Total Factor Productivity. J. Agrotech. Econ. 2019, 9, 4-13.

73. Zhang, H.L.; Li, J.Y. The Impact of Agricultural Technology Progress, Rural Labor Transfer and The Income Gap between Urban and Rural Areas: Study and Analysis on the Grouping of Agricultural Labor Productivity. East China Econ. Manag. 2020, 34, 69-75.

74. Ma, H.L.; Chou, N.T.; Wang, L. Dynamic Coupling Analysis of Urbanization and Water Resource Utilization Systems in China. Sustainability 2016, 8, 1176. [CrossRef]

75. Zhang, K.; Deng, X.; Shen, Q.L.; Qi, Y.B. Agricultural Technology Progress, Rural Labor Transfer, and Farmers' Income-Analysis of Group PVAR Model Based on Agricultural Labor Productivity. J. Agrotech. Econ. 2017, 6, $28-41$.

76. Lu, H.; Xie, H.L.; Yao, G.G. Impact of Land Fragmentation on Marginal Productivity of Agricultural Labor and Non-agricultural Labor Supply: A Case Study of Jiangsu, China. Habitat Int. 2019, 83, 65-72. [CrossRef]

77. Bao, C.; Zhou, J.J. Exploring the Coupling and Decoupling Relationships between Urbanization Quality and Water Resources Constraint Intensity: Spatiotemporal Analysis for Northwest China. Sustainability 2017, 9, 1960. [CrossRef]

78. Jiang, S.S. Interactive Development of China's Industrialization and Agricultural Modernization under the Background of New Urbanization. Soc. Sci. 2017, 6, 85-89.

79. Hao, Y.F.; Wang, Z.B. Does Agglomeration of Productive Services Contribute to High-quality Agricultural Growth? J. Humanit. 2019, 5, 54-61.

80. Yang, L.; Yang, F. "Feedback" or "Siphon"-Research on the Relationship between Industry and Agriculture in China's Resource-based Cities. Contemp. Econ. Manag. 2019, 41, 1-9.

81. Liu, M.H.; Lu, F. Agricultural and Industrial Sector: Feeding Each Other or Back-feeding-A study Based on Spatial Durbin Model. Rev. Econ. Manag. 2017, 33, 153-161.

82. Wan, G.H.; Yang, D.; Zhang, Y. Why Asia and China have Lower Urban Concentration and Urban Primacy. J. Asia Pac. Econ. 2017, 22, 90-105. [CrossRef]

83. Brezzi, M.; Veneri, P. Assessing Polycentric Urban Systems in the OECD: Country, Reginal and Metropolitan Perspectives. Eur. Plan. Stud. 2015, 23, 1128-1145. [CrossRef]

84. Li, Y.; Shao, H.; Jiang, N.; Shi, G.; Cheng, X. The Evolution of the Urban Spatial Pattern in the Yangtze River Economic Belt: Based on Multi-Source Remote Sensing Data. Sustainability 2018, 10, 2733. [CrossRef]

85. Zhou, W.; Yu, Z.B.; Lian, J. Measurement Indicators and Influencing Factors of Urban Population Concentration-Regression Analysis of the Impact of China's Economic Development on Urban Population Concentration. Inq. Econ. Issues 2007, 3, 32-37.

86. Chen, W.Z. Empirical Study Theoretical and Evidence on the Optimal Scale of Urban Primacy Ratio. Stat. Decis. 2017, 5, 126-129.

87. Jin, Y.T. A study on the Impact of Urban Prime Position on the Urban-rural Income Gap-An Empirical Analysis Based on China's Provincial Panel Data. Contemp. Econ. 2017, 9, 35-37. 
88. Wallace, J.S. Increasing Agricultural Water Use Efficiency to Meet Future Food Production. Agric. Ecosyst. Environ. 2000, 82, 105-119. [CrossRef]

89. Mancosu, N.; Snyder, R.L.; Kyriakakis, G.; Spano, D. Water Scarcity and Future Challenges for Food Production. Water 2015, 7, 975-992. [CrossRef]

90. Lu, Y.; Zhang, X.Y.; Chen, S.Y.; Sun, H.Y. Changes in Water Use Efficiency and Water Footprint in Grain Production over the Past 35 Years: A Case Study in the North China Plain. J. Clean. Prod. 2016, 116, 71-79. [CrossRef]

91. Pan, J.F.; Liu, Y.Z.; Zhong, X.H.; Lampayan, R.M.; Singleton, G.R.; Huang, N.R.; Liang, K.M.; Peng, B.L.; Tian, K. Grain Yield, Water Productivity and Nitrogen Use Efficiency of Rice under Different Water Management and Fertilizer-N Inputs in South China. Agric. Water Manag. 2017, 184, 191-200. [CrossRef]

(C) 2020 by the authors. Licensee MDPI, Basel, Switzerland. This article is an open access article distributed under the terms and conditions of the Creative Commons Attribution (CC BY) license (http://creativecommons.org/licenses/by/4.0/). 